\title{
Regeneration and Agrobacterium-mediated transformation of multiple lily cultivars
}

\author{
Yue Wang • Bernadette van Kronenburg • \\ Tila Menzel · Chris Maliepaard $\cdot$ Xiaohui Shen · \\ Frans Krens
}

Received: 13 January 2012/Accepted: 4 May 2012/Published online: 25 May 2012

(C) The Author(s) 2012. This article is published with open access at Springerlink.com

\begin{abstract}
To pursue genetic improvement of lily, efficiency of both regeneration and transformation from callus cultures induced from different explants were evaluated in multiple cultivars. Thirty-five callus lines induced from filaments or styles and one control callus line derived from bulb scales of in total twenty lily cultivars representing Lilium longiflorum, Oriental $\times$ Trumpet and Longiflorum $\times$ Asiatic hybrids were maintained on a medium with $8.3 \mu \mathrm{M}$ picloram (PIC). In this study, they were tested for their regeneration potential by transferring them onto a regeneration medium supplemented with $0.4 \mu \mathrm{M}$ PIC and $0.044 \mu \mathrm{M}$ 6-benzyladenine. Regeneration was obtained in all cultivars examined and the percentage varied from zero to $89 \%$ in the 36 callus lines. Regeneration frequency was significantly influenced by the genotype (cultivar). Subculturing the calli every 4 weeks by refreshing the regeneration medium contributed positively to bulblet formation, when compared to an eight week subculture frequency. It was found that the regeneration ability generally decreased with an increasing age of the callus cultures for all cultivars. The origin of the callus (style or filament) did not lead to significant differences in regeneration frequency, but there was an interaction between callus origin and genotype. Calli of eight randomly chosen cultivars were co-cultivated with Agrobacterium tumefaciens strain AGL0 carrying binary vectors with the gus gene as reporter and
\end{abstract}

Y. Wang $\cdot$ X. Shen $(\bowtie)$

School of Agriculture and Biology, Shanghai Jiao Tong

University, No. 800 Dongchuan Road, Shanghai 200240, China

B. van Kronenburg · T. Menzel · C. Maliepaard · F. Krens ( $\square)$

Wageningen UR Plant Breeding, Wageningen University and

Research Centre, P.O. Box 16, 6700 AA Wageningen,

The Netherlands

e-mail: frans.krens@wur.nl putative transgenic plants were produced. GUS histochemical assays demonstrated transient and stable expression of the gus gene in both calli and regenerated lily plants. Transient expression frequencies ranged from 0.3 to $20.6 \%$ while stable transformation was much lower, only $1.4 \%$ as the maximum.

Keywords Lily cultivars - Oriental hybrids - Callus · Regeneration · Transformation · GUS assay

$\begin{array}{ll}\text { Abbreviations } \\ \text { MS } & \text { Murashige and Skoog } \\ \text { 6-BA } & \text { 6-benzylaminopurine } \\ \text { PIC } & \text { Picloram, 4-amino-3,5,6-trichloropicolinic acid } \\ \text { CIM } & \text { Callus induction medium } \\ \text { RM } & \text { Regeneration medium } \\ \text { GUS } & \beta \text {-glucuronidase } \\ \text { MES } & \text { 2-(N-morpholino)ethanesulfonic acid }\end{array}$

\section{Introduction}

Lilies, Lilium spp., are of importance in floriculture due to their ornamental value as cut flowers, pot plants as well as garden plants (Robinson and Firoozabady 1993). New lily cultivars with improved qualities such as resistance to insects and diseases, novel flower color as well as longevity, are desirable for both producers and consumers (Chandler and Brugliera 2011; Cohen 2011). Genetic modification has been proven to be an alternative to conventional breeding for the introduction of such traits of interest into ornamental crops (Chandler and Brugliera 2011) and is also expected to benefit lily breeding. 
Lilies are among monocotyledonous plants that were thought to be recalcitrant to genetic transformation by Agrobacterium tumefaciens. Ever since Langeveld et al. (1995) reported the expression of the gus gene in inoculated stems, numerous efforts have been made to develop an efficient Agrobacterium-mediated transformation protocol. In recent years, successful lily transformation protocols have been reported (Azadi et al. 2010; Azadi et al. 2011; Hoshi et al. 2004; Hoshi et al. 2005; Liu et al. 2011; Núñez de Caceres et al. 2011; Ogaki et al. 2008), although the transformation efficiencies differed and mostly were low. To date, most studies were limited to only very few cultivars from Lilium longiflorum (Hoshi et al. 2005; Liu et al. 2011; Ogaki et al. 2008), L. x formolongi (Azadi et al. 2010) and Oriental hybrids (Azadi et al. 2010; Hoshi et al. 2004; Hoshi et al. 2005; Núñez de Caceres et al. 2011). The potential of a larger number of elite cultivars from prominent sections in the market such as Oriental and OT hybrids has not been fully investigated.

For successful production of genetically modified lily plants, one prerequisite is the establishment of a transformation protocol based on regeneration and transformation competence of cells. The efficiency of such a protocol depends on the genotype, explant origin, age and culture condition (Fay 1994). The aim of present research was to examine the regeneration capacity of long-term in vitro propagated callus cultures in 20 cultivars, representing L. longiflorum, Oriental, OT and LA hybrids. For this, the effect of the age of the callus cultures and the callus subculture frequency were studied for the calli of two origins (filament or style). In addition, the Agrobacterium-mediated transformation efficiency was determined in eight cultivars.

\section{Materials and methods}

\section{Plant materials}

Twenty lily cultivars, including thirteen cultivars from Oriental hybrids, three from L. longiflorum, three from OT hybrids and one LA hybrid, were used as shown in Tables 1 and 2. Callus induction from these cultivars was done in 2008 essentially as described by Hoshi et al. (2004) with minor modifications. In addition to filaments, styles were used as an explant to induce callus in 2008 and the callus cultures originating from these two tissue types were maintained separately and tested individually. All calli of both origins were maintained by subculturing to fresh callus induction medium (CIM) every 4 weeks. For L. longiflorum cv. 'Snow Queen', bulb scales were used to induce callus on CIM. CIM consisted of MS salts and vitamins (Murashige and Skoog 1962) supplemented with $30 \mathrm{~g} / \mathrm{L}$ sucrose, $3 \mathrm{~g} / \mathrm{L}$ Gelrite and $8.3 \mu \mathrm{M}$ picloram (PIC), pH 5.8 (Hoshi et al. 2004).
Regeneration ability experiments

For regeneration experiments, calli were collected at the end of a 4-week subculture period, cut into small pieces (about $3 \mathrm{~mm}$ ) and placed on regeneration medium (RM) to test the regeneration ability. RM consisted of MS medium supplemented with $30 \mathrm{~g} / \mathrm{L}$ sucrose, $3 \mathrm{~g} / \mathrm{L}$ Gelrite, $0.4 \mu \mathrm{M}$ PIC plus $0.044 \mu \mathrm{M}$ 6-benzyladenine (6-BA), pH 5.8 (Hoshi et al. 2004). For each callus origin of each cultivar in all experiments, 100 calli, i.e. four replications with 25 pieces of callus per replication on one dish were used.

Regeneration ability was examined in both 2009 and 2010, i.e. 12 and 18 months after callus initiation respectively, representing a 6 months difference in age. In 2009, calli were incubated on RM with an 8 weeks subculture frequency. This was repeated in 2010, so with the same subculture frequency as in 2009. In the same experiments in 2010, calli were also subcultured on RM with a four week interval in order to monitor the effect of increasing the subculture frequency. All cultures were kept in the dark at $25{ }^{\circ} \mathrm{C}$. The number of regenerative calli producing bulblets was recorded after 8 weeks of culture on RM to calculate regeneration frequency.

\section{Agrobacterium-mediated transformation}

Callus of eight cultivars was transformed with Agrobacterium tumefaciens strain AGL0 (Lazo et al. 1991) carrying binary vectors pCAMBIA1301 + GUS (CAMBIA, Australia) or pMF2 + GUS (Schaart et al. 2010). The first vector can be considered as a model vector for protocol testing with a hygromycin resistance gene, $h p t$, as selectable marker and the gus gene as reporter for gene transfer both under control of the CaMV35S promoter. The second vector was derived from pMF1, with a hpt gene under control of the CaMV35S promoter inserted in the unique SpeI site of pMF1. This vector allows the generation of marker-free genetically modified plants. In this particular study, the gene-of-interest is the reporter gene, gus, under control of the chrysanthemum small subunit rubisco promoter (Outchkourov et al. 2003). The transformation method was based on the protocol described by Hoshi et al. (2004) with modifications in callus wounding and co-cultivation medium. Calli were wounded by cutting them into small pieces with a scalpel. The solidified co-cultivation medium was replaced with 3 layers of sterile filter paper wetted with $5 \mathrm{ml}$ of liquid co-cultivation medium. Calli inoculated with an Agrobacterium suspension at an OD of 0.5-0.7 were placed with adhering agrobacteria on these wet papers for co-cultivation for 7 days, followed by transfer to selection medium. Selection medium consisted of regeneration medium supplemented with $250 \mathrm{mg} / \mathrm{L}$ cefotaxime and $150 \mathrm{mg} / \mathrm{L}$ timentin to eliminate the overgrowth of agrobacteria and with $15 \mathrm{mg} / \mathrm{L}$ hygromycin to select for transgenic regenerants. 
Table 1 Bulblet regeneration frequencies in 2009 and 2010 representing a callus age of 12 and 18 months respectively

\begin{tabular}{|c|c|c|c|c|c|c|}
\hline \multirow[t]{2}{*}{ Section and hybrids } & \multirow[t]{2}{*}{ Cultivar } & \multicolumn{3}{|c|}{ Regeneration frequency (\%) in 2009} & \multicolumn{2}{|c|}{ Regeneration frequency (\%) in 2010} \\
\hline & & Filament & Style & & Filament & Style \\
\hline \multirow[t]{2}{*}{ L. longiflorum } & White Fox & $4(4.62)$ & 0 & & $2(2.31)$ & $1(2.00)$ \\
\hline & White Heaven & $20(5.66)$ & - & & $8(4.00)$ & - \\
\hline \multirow[t]{13}{*}{ Oriental hybrids } & Barbados & $61(10.52)$ & $62(13.27)$ & & $25(8.25)$ & $26(2.31)$ \\
\hline & Burlesca & $67(14.38)$ & $80(13.86)$ & & $29(2.00)$ & $48(11.78)$ \\
\hline & Cherbourg & $64(8.64)$ & $19(8.87)$ & & $36(11.31)$ & $15(2.00)$ \\
\hline & Gracia & 89 (12.38) & $87(16.12)$ & & $37(10.00)$ & $53(6.83)$ \\
\hline & Lake Carey & $50(16.81)$ & $39(15.10)$ & & $31(7.57)$ & $30(12.44)$ \\
\hline & Lexus & $70(15.49)$ & $72(14.24)$ & & $76(8.64)$ & $57(3.83)$ \\
\hline & Montezuma & $15(8.87)$ & $31(8.87)$ & & $32(8.64)$ & $20(3.27)$ \\
\hline & Paradero & $29(13.22)$ & 34 (13.27) & & $15(6.83)$ & $27(6.83)$ \\
\hline & Santander & $60(6.53)$ & $75(13.22)$ & & $8(3.27)$ & $30(2.31)$ \\
\hline & Sheila & - & $63(14.00)$ & & - & $24(5.66)$ \\
\hline & Sorbonne & $19(6.00)$ & $41(13.61)$ & & $5(2.00)$ & $12(5.66)$ \\
\hline & White Express & $70(12.00)$ & $16(6.53)$ & & $32(4.62)$ & $7(3.83)$ \\
\hline & Top White & $54(16.81)$ & $50(24.77)$ & & $42(10.58)$ & $45(5.03)$ \\
\hline \multirow[t]{3}{*}{ OT hybrids } & Yelloween & $57(13.22)$ & $40(13.86)$ & & $20(5.66)$ & $20(11.31)$ \\
\hline & Lesotho & $44(11.31)$ & $39(15.10)$ & & $17(5.03)$ & $13(6.00)$ \\
\hline & Robina & $27(6.83)$ & $27(19.70)$ & & $4(0.0)$ & $10(2.31)$ \\
\hline LA hybrids & Brindisi & - & $76(5.66)$ & & $21(5.03)$ & - \\
\hline Source & & Likelihood ratio Chi-square & & $d f$ & Sig. & $\mathrm{F}$ \\
\hline \multicolumn{7}{|l|}{ Statistical analysis } \\
\hline Cultivars* & & 61.1189 & & 19 & $<0.001$ & 50.585 \\
\hline Callus origin & & 1.289 & & 1 & 0.256 & 1.289 \\
\hline Age* & & 250.468 & & 1 & $<0.001$ & 250.468 \\
\hline Cultivars $\times$ Callus origin $*$ & & 119.976 & & 15 & $<0.001$ & 7.998 \\
\hline
\end{tabular}

Subculture was every 8 weeks

The standard errors of means based on the percentages of four replicates are given in parentheses

- Not determined

* Significant difference at an alpha level of 0.05

For each callus line of each cultivar, 100 calli were used in regeneration experiments

Table 2 Regeneration frequencies from bulb scale-derived callus of 'Snow Queen'

\begin{tabular}{lcll}
\hline $\begin{array}{l}\text { L. } \\
\text { longiflorum }\end{array}$ & $2009(\%)$ & $\begin{array}{l}2010 \\
\text { without } \\
\text { refreshment } \\
(\%)\end{array}$ & $\begin{array}{l}\text { 2010 with } \\
\text { refreshment } \\
(\%)\end{array}$ \\
\hline Snow Queen & 43 & $9(5.03)$ & $11(6.83)$ \\
& $(12.81)$ & & \\
\hline
\end{tabular}

The standard errors of means based on the percentages of four replicates are given between parentheses

GUS histochemical assay

Calli after 7 days on co-cultivation medium and plants regenerated on selection medium and collected for testing after approximately 12 months were stained histochemically for GUS activity according to Jefferson (1987) as an indicator for transient (after 7 days) and stable (after 12 months of selection) gene transfer efficiency, respectively. The number of calli with blue spots (after 7 days) and plantlets showing a totally blue-stained (GUS +) phenotype (after 12 months) were recorded.

Statistical analysis

Statistical analyses for regeneration and transformation with AGL0(pMF2 + GUS) were analyzed using Generalized Linear Models with PASW Statistics 18. The numbers of regenerative calli and GUS + calli were the response variable respectively when binomial distribution and logit 
link were used. The significances of factors and interactions were tested at an alpha level of 0.05 by Likelihood ratio Chi-square tests. The effects of cultivar, callus origin and age and the interaction between cultivar and callus origin were based on data in 2009 and 2010 without medium refreshment. The effect of refreshment was based on data in 2010. The effects of cultivar and callus origin were also detected in 2010 with refreshment. 'Snow Queen' was separately analyzed due to its deviating callus origin.

\section{Results}

Regeneration

\section{Cultivar effect}

Thirty-six callus lines from 20 cultivars maintained by subculture were evaluated for the regeneration potential to form bulblets (Tables 1,2). About 2 weeks after culture on $\mathrm{RM}$, regeneration was observed via direct bulblet formation from the surface of the calli. Bulblet formation could be obtained in all 19 cultivars examined and the regenerative capacity varied considerably as shown in Table 1 . For the cultivar 'Snow Queen', the callus was generated on bulb scales instead of on filaments or styles, hence the regeneration data of 'Snow Queen' are presented separately in Table 2 . The highest percentage of up to $89 \%$ occurred in 'Gracia' filament originated callus after 8 weeks of culture on RM, followed by 'Brindisi', 'Burlesca' and 'Lexus' in 2009. Statistical analysis demonstrated that differences between cultivars were significant in both 2009 and 2010 (Table 1).

\section{Callus age effect}

Effect of callus age on the bulblet regeneration from filament-derived and style-derived calli is also shown in Table 1. It was observed that callus age negatively influenced the regeneration potential. In all callus lines except 'Lexus' and 'Montezuma' filament originated callus after 8 weeks of culture on RM in 2010, when compared to the data of 2009. We found this difference in regeneration related to the age of calli to be statistically significant (Table 1).

\section{Effect of subculture frequency}

It was found that subculturing the callus lines to fresh RM every after 4 weeks played a significant role in callus regeneration (Table 3) when compared to subculturing every 8 weeks. In most cases, the increase in frequency was beneficial to regeneration as there was an increase in the number of regenerative calli (Fig. 1). The greatest increase was obtained in 'Lesotho' styles, from 13 to $54 \%$. However, in a few cases such as 'Yelloween' styles, no increase in produced bulblets was observed despite the transfer to fresh RM after 4 weeks.

\section{Callus origin effect}

In Table 1, two callus origins, either from filaments or from styles presented similar regeneration efficiencies in most cultivars. For instance, filament and styles derived calli of cultivar 'Gracia' had high regeneration efficiency, up to 87 and $89 \%$, respectively while cultivar 'Robina' displayed very low $(27 \%)$ regeneration efficiency in both calli. In a few cases, e.g. cultivars 'Cherbourg' and 'White Express', filament-derived callus showed higher regeneration abilities than callus from styles. There was no statistically significant difference between callus origins when calli were cultured on RM for 8 weeks without medium refreshment (Table 1). However, with medium refreshment in 2010, the origin of the callus did show a significant effect on regeneration (Table 3 ). In six cultivars, filaments showed significantly higher regeneration than styles.

Besides the single effect of factors, we also detected the interaction between callus origin and genotype, which was found to be statistically significant (Table 1). Therefore, we compared the effect of the callus origin on the regeneration within each cultivar in 2009. It was found that in ten cultivars no significant difference was observed while three cultivars were higher for styles and the other three were higher for filaments. Therefore, the regeneration potential really depended on both the genotype and callus origin.

\section{GUS histochemical assay}

The results of histochemical staining demonstrated that the gus gene was functional in the lily cultivars that were examined. Blue spots were observed in all fifteen callus lines seven days after co-cultivation with AGLO(pCAMBIA1301 + GUS) (Table 4), indicating successful gene delivery and transient expression. The percentage of GUS + calli ranged from 0.5 to $11.5 \%$, and the number of spots (data not shown) varied with the cultivars as well as with callus origins. 'Lake Carey' styles performed best, followed by 'Sheila' filaments. However, no transgenic plants were obtained in this experiment.

When transformation was done using strain AGL0 (pMF2 + GUS), it was found that twelve out of fifteen callus lines from seven out of eight cultivars showed blue spots (Table 5). Transient expression of the gus gene was 
Table 3 Bulblet regeneration frequencies in 2010 with subculture every 4 weeks

\begin{tabular}{|c|c|c|c|c|}
\hline Section and hybrids & Cultivar & Filament $(\%)$ & & Style $(\%)$ \\
\hline \multirow[t]{2}{*}{ L. longiflorum } & White Fox & $7(6.83)$ & & $2(4.00)$ \\
\hline & White Heaven & $12(8.64)$ & & - \\
\hline \multirow{13}{*}{ Oriental hybrids } & Barbados & $51(8.87)$ & & $34(9.52)$ \\
\hline & Burlesca & $66(10.58)$ & & $62(8.33)$ \\
\hline & Cherbourg & $58(17.44)$ & & $45(10.52)$ \\
\hline & Gracia & $41(8.87)$ & & $56(7.30)$ \\
\hline & Lake Carey & $58(12.44)$ & & $59(6.83)$ \\
\hline & Lexus & $83(5.03)$ & & $65(15.10)$ \\
\hline & Montezuma & $50(6.93)$ & & $20(7.30)$ \\
\hline & Paradero & $31(14.38)$ & & $26(8.33)$ \\
\hline & Santander & $25(6.83)$ & & $38(10.58)$ \\
\hline & Sheila & - & & $50(10.58)$ \\
\hline & Sorbonne & $32(5.66)$ & & $38(17.74)$ \\
\hline & White Express & $60(7.30)$ & & $7(3.27)$ \\
\hline & Top White & $48(10.33)$ & & $66(12.44)$ \\
\hline \multirow[t]{3}{*}{ OT hybrids } & Yelloween & $39(15.10)$ & & $20(5.66)$ \\
\hline & Lesotho & $39(10.00)$ & & $54(19.18)$ \\
\hline & Robina & $8(3.27)$ & & $13(5.03)$ \\
\hline LA hybrids & Brindisi & $31(5.03)$ & & - \\
\hline Source & Likelihood ratio Chi-square & $\mathrm{F}$ & $d f$ & Sig. \\
\hline \multicolumn{5}{|l|}{ Statistical analysis } \\
\hline Cultivars* & 1721.371 & 90.598 & 19 & $<0.001$ \\
\hline Callus origin* & 5.945 & 5.945 & 1 & 0.015 \\
\hline Refreshment* & 188.207 & 188.207 & 1 & $<0.001$ \\
\hline Cultivars $\times$ Callus origin $*$ & 196.484 & 13.099 & 15 & $<0.001$ \\
\hline
\end{tabular}

The standard errors of means based on the percentages of four replicates are given between parentheses

- Not detected

* Significant difference at an alpha level of 0.05

observed in both filament-derived and style-derived calli of five cultivars, ranging from 0.3 to $20.64 \%$. Callus from 'Snow Queen' bulb scales, 'Yelloween' filaments and 'Santander' styles failed to transiently express the gus gene. 'Barbados' filaments showed the highest number of GUS + calli, followed by 'Lake Carey'. Statistical analysis showed that there was a significant difference of GUS + calli between cultivars and callus origins. Seventeen transgenic plants, i.e. stained blue all-over after 12 months on selection indicating stable transformation, were obtained from eight callus lines of six cultivars (Fig. 2). No transgenic plants were obtained from 'Barbados' filaments despite the highest transient expression with the highest GUS + percentage in calli after co-cultivation. One transgenic plant was obtained from 'Yelloween' filaments despite that earlier no callus showed blue spots after co-cultivation, transiently. Although transgenic plants could be obtained from eight callus lines, the transformation efficiency was low in most lines.

\section{Discussion}

Lilies have been proven to be amenable to regeneration in vitro while they are recalcitrant to transformation by Agrobacterium tumefaciens. To date, only a limited number of cultivars have been successfully used in transformation with the most common ones from L. longiflorum, L. $x$ formolongi and a few Oriental hybrids (Azadi et al. 2010; Hoshi et al. 2004; Hoshi et al. 2005; Liu et al. 2011). The present study simultaneously demonstrated the regeneration capacity of flower-organ induced callus in 20 cultivars representing four hybrid origins and the efficiencies of Agrobacterium-mediated transformation in eight cultivars, randomly selected from them.

The regeneration potential of cultures has been found to be affected by multiple factors and 'cultivar' is considered to be an important factor, if not the major one (Redway et al. 1990; this study). In the 20 cultivars examined in the present study, marked differences were observed in 

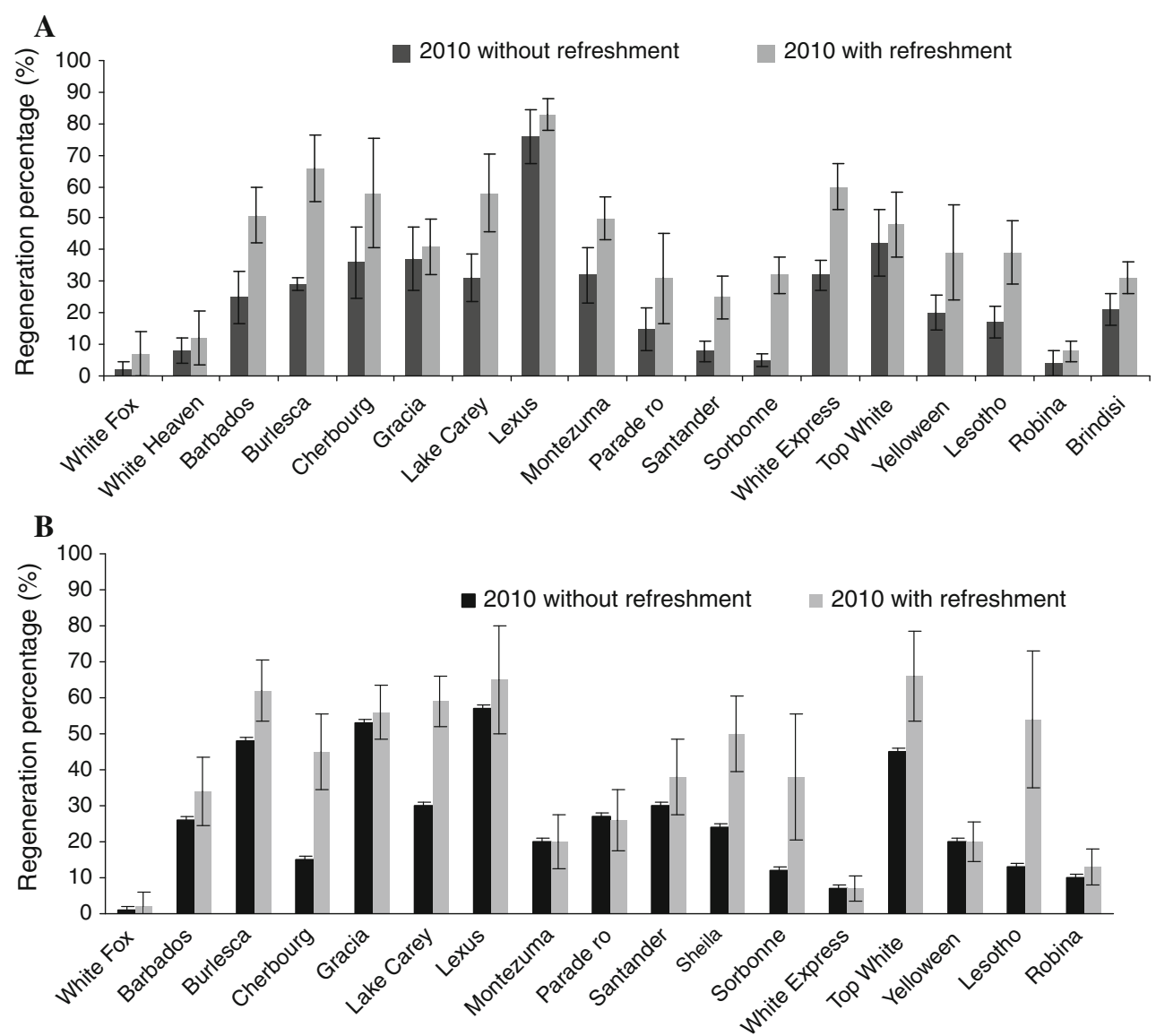

Fig. 1 The effect of subculture frequency on regeneration scored after 8 weeks. The experiments were performed in 2010. Without refreshment means subculture every 8 weeks and with refreshment means subculture every 4 weeks. a Regeneration from filamentderived calli obtained from eighteen cultivars. b Regeneration from style-derived calli obtained from seventeen cultivars
Table 4 GUS staining after the co-cultivation period of seven days (strain AGLO $($ pCAMBIA1301 + GUS $))$

\begin{tabular}{lllllc}
\hline Cultivar & Callus origin & $\begin{array}{l}\text { No. of stained } \\
\text { calli }\end{array}$ & $\begin{array}{l}\text { No. of } \\
\text { GUS + calli }\end{array}$ & $\begin{array}{l}\text { No. of } \\
\text { GUS + spots }\end{array}$ & $\begin{array}{c}\text { \% of } \\
\text { GUS + calli }\end{array}$ \\
\hline Barbados & Filament & 200 & 7 & 31 & 3.5 \\
& Style & 200 & 1 & 1 & 0.5 \\
Gracia & Filament & 100 & 3 & 7 & 3.0 \\
& Style & 100 & 7 & 24 & 7.0 \\
Lake Carey & Filament & 200 & 10 & 23 & 5.0 \\
& Style & 200 & 23 & 79 & 11.5 \\
Santander & Filament & 200 & 4 & 11 & 2.0 \\
& Style & 150 & 7 & 20 & 4.7 \\
Sheila & Filament & 100 & 10 & 17 & 10.0 \\
\multirow{3}{*}{ Snow Queen } & Style & 100 & 6 & 8 & 6.0 \\
Sorbonne & Bulb scale & 200 & 4 & 13 & 2.0 \\
& Filament & 200 & 2 & 5 & 1.0 \\
Yelloween & Style & 200 & 2 & 2 & 5.0 \\
& Filament & 200 & 11 & 44 & 1.3 \\
\hline
\end{tabular}


Table 5 Efficiency of AGL0(pMF2 + GUS)-mediated transformation in eight lily cultivars

\begin{tabular}{|c|c|c|c|c|c|c|c|}
\hline Cultivar & $\begin{array}{l}\text { Callus } \\
\text { origin }\end{array}$ & $\begin{array}{l}\text { No. of calli } \\
\text { tested }\end{array}$ & $\begin{array}{l}\text { No. of } \\
\text { GUS }+ \text { calli }\end{array}$ & $\begin{array}{l}\text { No. of } \\
\text { GUS }+ \text { spots }\end{array}$ & $\begin{array}{l}\% \text { of GUS }+ \text { calli } \\
(\mathrm{t}=7 \text { days })\end{array}$ & $\begin{array}{l}\text { No. of GUS }+ \text { plants } \\
(\mathrm{t}=12 \text { months })\end{array}$ & \\
\hline \multirow[t]{2}{*}{ Barbados } & Filament & 280 & 52 & 100 & $20.64(22.42)$ & 0 & \\
\hline & Style & 540 & 23 & 36 & $6.82(5.04)$ & 1 & \\
\hline \multirow[t]{2}{*}{ Gracia } & Filament & 670 & 10 & 27 & 1.80 (1.69) & 0 & \\
\hline & Style & 475 & 3 & 4 & $0.71(1.24)$ & 0 & \\
\hline \multirow{2}{*}{$\begin{array}{l}\text { Lake } \\
\text { Carey }\end{array}$} & Filament & 310 & 27 & 52 & $7.82(4.44)$ & 1 & \\
\hline & Style & 445 & 32 & 32 & $4.79(4.18)$ & 3 & \\
\hline \multirow[t]{2}{*}{ Santander } & Filament & 355 & 3 & 5 & $0.64(0.56)$ & 5 & \\
\hline & Style & 290 & 0 & 0 & $0(0)$ & 0 & \\
\hline \multirow[t]{2}{*}{ Sheila } & Filament & 435 & 2 & 2 & $0.44(0.77)$ & 0 & \\
\hline & Style & 420 & 1 & 2 & $0.30(0.52)$ & 3 & \\
\hline $\begin{array}{l}\text { Snow } \\
\text { Queen }\end{array}$ & Bulb scale & 215 & 0 & 0 & $0(0)$ & 0 & \\
\hline \multirow[t]{2}{*}{ Sorbonne } & Filament & 510 & 11 & 28 & $2.6(1.63)$ & 2 & \\
\hline & Style & 420 & 2 & 3 & $0.61(1.05)$ & 0 & \\
\hline \multirow[t]{2}{*}{ Yelloween } & Filament & 410 & 0 & 0 & $0(0)$ & 1 & \\
\hline & Style & 740 & 4 & 11 & $0.67(1.15)$ & 1 & \\
\hline \multicolumn{2}{|l|}{ Source } & \multicolumn{3}{|c|}{ Likelihood ratio Chi-square } & $d f$ & Sig. & $\mathrm{F}$ \\
\hline \multicolumn{8}{|c|}{ Statistical analysis } \\
\hline \multicolumn{2}{|l|}{ Cultivars* } & \multicolumn{2}{|c|}{64.547} & & 7 & $<0.001$ & 9.221 \\
\hline \multicolumn{2}{|c|}{ Callus origin* } & \multicolumn{2}{|c|}{8.797} & & 1 & 0.003 & 8.797 \\
\hline
\end{tabular}

The standard errors of means based on the percentages of three replicates are given between parentheses

* Significant difference at an alpha level of 0.05

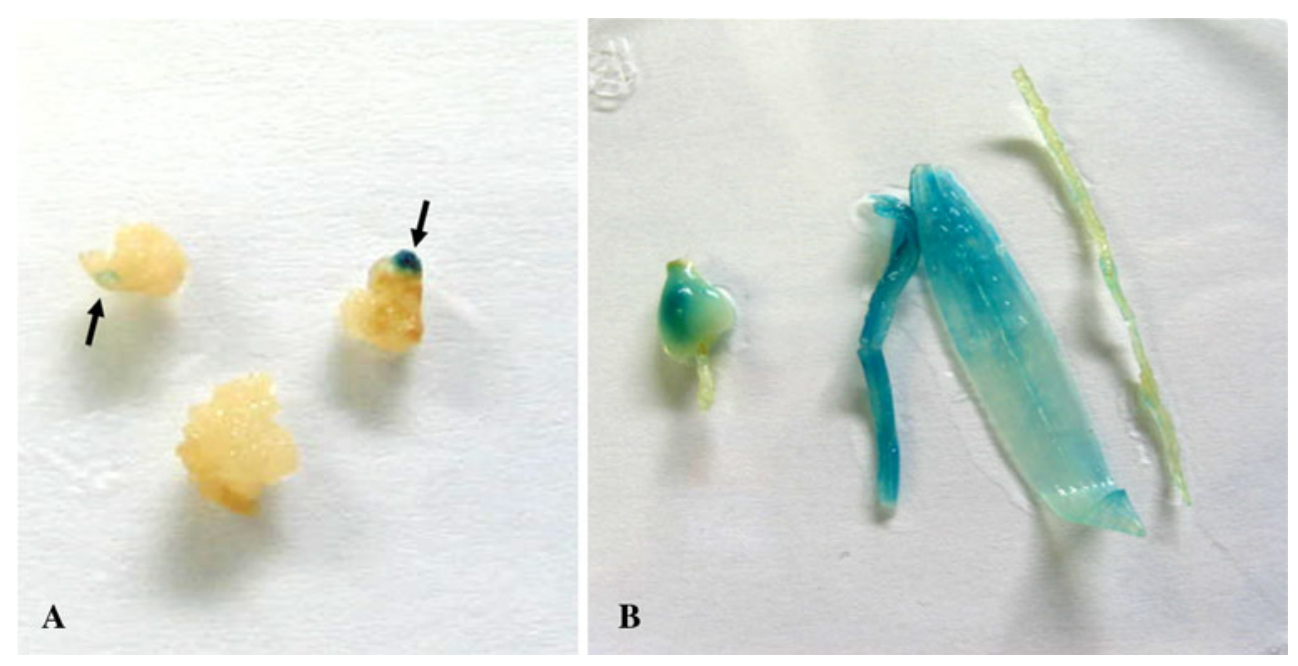

Fig. 2 GUS staining of calli and regenerated plants. a Calli with blue stained areas (arrows top two calli, left faint expression, right high expression) and control callus (bottom one) showing no staining at all.

regeneration efficiency from in vitro propagated calli. Similar results about regeneration differences of callus cultures among genotypes in lilies were reported by Mori et al. (2005). b Individual plant organs showing blue, GUS positive staining obtained from a regenerated transgenic lily plant; from left to right: a bulb scale, two leaflets and a root

To date, different explants have been used for callus induction in lilies, mainly including bulb scales, filaments, leaves and seeds (Mori et al. 2005). The use of stylederived callus has been reported only by Tribulato et al. 
(1997). In our study, both filament-derived and stylederived callus cultures were used. The regenerative capacity of style-derived callus proved to be comparable to filament-derived callus. Therefore, when preparing callus suitable for regeneration by using flower parts as the explant source, styles can be used in addition to filaments as explants, broadening the source of callus and speeding up the generation of sufficient amounts of callus for further research. In a few cultivars, there was a significant difference in regeneration based on the callus origin, e.g. in 'Cherbourg', 'White Express', and 'Yelloween', whose filaments showed higher frequencies than styles.

The low response in some cultivars in the regeneration of bulblets might be caused by the long-term maintenance in culture. In our initial experiments (Krens et al. 2009), these callus lines had a high regeneration capacity. However, after maintenance for one to 1.5 years, they showed a decrease in regeneration potential. The reduction in the regeneration potential with increasing time of subculture had already been reported in lily suspension cells (Nakano et al. 2000) and in other plants, such as wheat (Redway et al. 1990). This could be due to physiological changes in the cells (Nakano et al. 2000).

In 2009, callus was cultured on RM for a period of 8 weeks without subculturing as suggested by Mori et al. (2005). In 2010, we compared the effect of increasing subculture frequency to once every four 4 weeks, and it was found that this increase significantly improved the regeneration response.

In summary, all factors studied including cultivar, age, callus origin and refreshing RM after 4 weeks, proved to be important in determining the regeneration efficiency.

Hoshi et al. (2004) first reported the successful production of transgenic lilies by Agrobacterium-mediated transformation using filament callus. In our study, we applied the protocol with a few, but important modifications. Firstly, we expanded the flower parts used as origin of callus amenable for transformation and proved that in addition to filaments also styles can be used successfully. Secondly, our cocultivation was done on wet filter paper instead of on agar-solidified medium and scarification was performed by chopping with a scalpel as opposed to shaking in sand-paper covered centrifuge tubes. The cocultivation on filter paper was introduced because preliminary experiments testing more stressful conditions during cocultivation, i.e. more dry by raising Gelrite concentrations up to $10 \%(\mathrm{w} / \mathrm{v})$ as described by Hoshi et al. (2005) or by replacing solidified media by wetted paper, showed some indications for higher transformation frequencies on the wetted filter paper (data not shown). We also investigated gene transfer in no less than eight cultivars, mainly Oriental hybrids, but also including one OT hybrid and one L. longiflorum, cv. 'Snow Queen' as the long-term reference in our lab (Benedito et al. 2005). To date, there have been a few reports aimed to increase transformation efficiency by optimizing the culture conditions in co-cultivation (Azadi et al. 2010; Hoshi et al. 2005; Ogaki et al. 2008). Ogaki et al. (2008) found that transient GUS expression and hygromycin-resistant transgenic calli were obtained only when 2-(N-morpholino)ethanesulfonic acid (MES) was added to co-cultivation medium. However, we applied co-cultivation medium without MES as suggested by Hoshi et al. (2004) and used liquid medium instead of a solid one, which produced both transient and stable GUS expression in multiple callus lines. Our stable transformation efficiencies were low, when compared with the recent reports by Liu et al. (2011) and Núñez de Caceres et al. (2011). This could be due to the differences in genotypes used or in details of the protocols. Therefore, further improvements in our transformation protocol could still be obtained in the future based on the information provided in those articles.

GUS assays are widely used as an indicator to monitor transformation capacity and gene transfer efficiency. Nontransgenic controls never showed blue staining, while sometimes GUS expression and staining can be lacking despite the fact that T-DNA has been integrated (Ramadan et al. 2011; Kumar et al. 2011). In the first transformants obtained with this protocol PCR showed the presence of gus gene sequences in totally blue-stained lily plants. Molecular analysis was not performed in this extension study, however, PCR and RT-PCR analysis on later transformants obtained using target genes (data not shown) confirmed once again the potential of this protocol to generate transgenic plants in lily as suggested by the GUS positive transformants described here. Two different vectors carrying the gus gene were used in transformation. For AGL0(pCAMBIA1301 + GUS), despite transient expression of the gus gene in all the 15 callus lines examined, transgenic, GUS positive plants could not be obtained. This probably indicated that the cells with transformation competency could not regenerate after co-cultivation or that gus gene expression was either lost, silenced or inhibited in regenerated plantlets. A similar failure in detecting GUS activity in tissues of transgenic wheat was reported (Ramadan et al. 2011), which could result from the presence of some potential GUS enzyme inhibitors in those tissues (Bahieldin et al. 2005; Ramadan et al. 2011). Kumar et al. (2011) found that the CaMV 35S promoter was ineffective in early stages of transgenic plant development in sorghum. Because of the lack of stably, GUS expressing transformed lily plants with the CAMBIA model vector, we switched to strain AGL0(pMF2 + GUS) which carries the gus gene under control of the very highly active chrysanthemum small subunit rubisco promoter (Outchkourov et al. 2003). Transient gus expression was 
also observed here, although frequencies varied for the different cultivars when compared to AGLO(pCAMBIA1301 + GUS). Stable, GUS positive plants could be obtained from multiple cultivars, including five Oriental hybrids and one OT hybrid. Moreover, we found that transgenic (GUS +) plants were also produced from the callus lines that showed low or even zero transient gus expression, while no GUS + plant was obtained from the callus line that exhibited relatively high percentage of transient gus expression. This indicated that the data on the production of stable, transgenic plants were not directly related to the transient data based on GUS histochemical assay shortly after co-cultivation. This could be due to conditions related to the integration of transgenes and to the regulation of gene expression in the tissue of regenerants after transformation (Pitzschke and Hirt 2010). In many species, e.g. in melon (Chovelon et al. 2011), a great difference was found between transient expression efficiencies and stable integration frequency. Also in other crops optimal conditions for transient and stable transformation are not always similar (De Bondt et al. 1994; Altpeter et al. 1996; Sandhu and Gosal 2009).

In conclusion, our research provided information on factors affecting lily regeneration in a broad range of cultivars and also on gene transfer for further studying transformation in the commercially most interesting lily hybrid cultivars, i.e., Orientals and OTs.

Acknowledgments Yue Wang was supported by a grant from the Chinese Scholarship Council. The research was supported financially by the Dutch Commodity Board for Horticulture.

Open Access This article is distributed under the terms of the Creative Commons Attribution License which permits any use, distribution, and reproduction in any medium, provided the original author(s) and the source are credited.

\section{References}

Altpeter F, Vasil V, Srivastava V, Stoger E, Vasil IK (1996) Accelerated production of transgenic wheat (Triticum aestivum L.) plants. Plant Cell Rep 16:12-17

Azadi P, Chin DP, Kuroda K, Khan RS, Mii M (2010) Macro elements in inoculation and co-cultivation medium strongly affect the efficiency of Agrobacterium-mediated transformation in Lilium. Plant Cell Tissue Organ Cult 101:201-209

Azadi P, Otang NV, Supaporn H, Khan RS, Chin DP, Nakamura I, Mii M (2011) Increased resistance to cucumber mosaic virus (CMV) in Lilium transformed with a defective CMV replicase gene. Biotechnol Lett 33:1249-1255

Bahieldin A, Eissa HF, Mahfouz HT, Dyer WE, Madkour MA, Qu $\mathrm{RD}$ (2005) Evidence for non-proteinaceous inhibitor(s) of $\beta$ glucuronidase in wheat (Triticum aestivum L.) leaf and root tissues. Plant Cell Tissue Organ Cult 82:11-17

Benedito VA, Kronenburg-Van Van, de Ven BCE, Van Tuyl J, Angenent GC, Krens FA (2005) Transformation of Lilium longiflorum via particle bombardment and generation of herbicide-resistant plants. Crop Breed Appl Biotechnol 5:259-264

Chandler SF, Brugliera F (2011) Genetic modification in floriculture. Biotechnol Lett 33:207-214

Chovelon V, Restier V, Giovinazzo N, Dogimont C, Aarrouf J (2011) Histological study of organogenesis in Cucumis melo L. after genetic transformation: why is it difficult to obtain transgenic plants? Plant Cell Rep 30:2001-2011

Cohen A (2011) Biotechnology in lilies-dreams vs. reality. Acta Hortic 900:149-160

De Bondt A, Eggermont K, Druart P, De Vil M, Goderis I, Vanderleyden J, Broekaert WF (1994) Agrobacterium-mediated transformation of apple (Malus x domestica Borkh.): an assessment of factors affecting gene transfer efficiency during early transformation steps. Plant Cell Rep 13:587-593

Fay MF (1994) In what situations is in vitro culture appropriate to plant conservation? Biodivers Conserv 3:176-183

Hoshi Y, Kondo M, Mori S, Adachi Y, Nakano M, Kobayashi H (2004) Production of transgenic lily plants by Agrobacteriummediated transformation. Plant Cell Rep 22:359-364

Hoshi Y, Kondo M, Kobayashi H, Mori S, Nakano M (2005) Agrobacterium-mediated transformation of Lilium longiflorum. Acta Hortic 673:543-547

Jefferson RA (1987) Assaying chimeric genes in plants: the GUS gene fusion system. Plant Mol Biol Rep 5:387-405

Krens FA, Menzel TR, Liu C, Dees DCT, van Kronenburg BCE (2009) Oriental lily hybrids engineered to resist aphid attack. Acta Hortic 836:253-258

Kumar V, Campbell LM, Rathore KS (2011) Rapid recovery- and characterization of transformants following Agrobacteriummediated T-DNA transfer to sorghum. Plant Cell Tissue Organ Cult 104:137-146

Langeveld SA, Gerrits MM, Derks FLM, Boonekamp PM, Bol JF (1995) Transformation of lily by Agrobacterium. Euphytica 85: 97-100

Lazo GR, Stein PA, Ludwig RA (1991) A DNA transformationcompetent Arabidopsis genomic library in Agrobacterium. Nat Biotechnol 9:963-967

Liu J, Zhang J, Xu B, Jia C, Zhang J, Tan G, Jin Z (2011) Regeneration and production of transgenic Lilium longiflorum via Agrobacterium tumefaciens. In Vitro Cell Dev-Plant 47:348-356

Mori S, Adachi Y, Horimoto S, Suzuki S, Nakano M (2005) Callus formation and plant regeneration in various Lilium species and cultivars. In Vitro Cell Dev-Plant 41:783-788

Murashige T, Skoog F (1962) A revised medium for rapid growth and bioassays with tobacco tissue cultures. Physiol Plant 15:473-497

Nakano M, Sakakibara T, Suzuki S, Saito H (2000) Decrease in the regeneration potential of long-term cell suspension cultures of Lilium formosanum Wallace and its restoration by the auxin transport inhibitor, 2,3,5-triiodobenzoic acid. Plant Sci 158:129_ 137

Núñez de Caceres FF, Davey MR, Wilson ZA (2011) A rapid and efficient Agrobacterium-mediated transformation protocol for Lilium. Acta Hortic 900:161-168

Ogaki M, Furuichi Y, Kuroda K, Chin DP, Ogawa Y, Mii M (2008) Importance of co-cultivation medium $\mathrm{pH}$ for successful Agrobacterium-mediated transformation of Lilium x formolongi. Plant Cell Rep 27:699-705

Outchkourov NS, Peters J, de Jong J, Rademakers W, Jongsma MA (2003) The promoter-terminator of chrysanthemum rbcS1 directs very high expression levels in plants. Planta 216:1003-1012

Pitzschke A, Hirt H (2010) New insights into an old story: Agrobacterium-induced tumour formation in plants by plant transformation. EMBO J 29:1021-1032

Ramadan AM, Eissa HF, El-Domyati FM, Saleh OM, Ibrahim NE, Salama M, Mahfouz MM, Bahieldin A (2011) Characterization 
of inhibitor(s) of $\beta$-glucuronidase enzyme activity in GUStransgenic wheat. Plant Cell Tissue Organ Cult 107:373-381

Redway FA, Vasil V, Lu D, Vasil IK (1990) Identification of callus types for long-term maintenance and regeneration from commercial cultivars of wheat (Triticum aestivum L.). Theor Appl Genet 79:609-617

Robinson KEP, Firoozabady E (1993) Transformation of floriculture crops. Sci Hortic 55:83-99

Sandhu JS, Gosal SS (2009) A simple and rapid method for optimizing particle bombardment parameters through transient expression of GUS reporter gene in onion epidermal layer cells. Crop Improv 36:6-8

Schaart JG, Krens FA, Wolters A-MA, Visser RGF (2010) Transformation methods for obtaining marker-free genetically modified plants (Chapter: 15). In: Stewart CN Jr, Touraev A, Citovsky V, Tzfira T (eds) Plant transformation technologies. Wiley-Blackwell, Hoboken, NJ, pp 229-242

Tribulato A, Remotti PC, Löffler HJM, van Tuyl JM (1997) Somatic embryogenesis and plant regeneration in Lilium longiflorum Thunb. Plant Cell Rep 17:113-118 